\section{The Framingham scores overestimated the risk for coronary heart disease in Japanese, Hispanic, and native American cohorts}

\author{
D'Agostino RB Sr, Grundy S, Sullivan LM, et al, for the CHD Risk Prediction Group. Validation of the Framingham \\ coronary heart disease prediction scores. Results of a multiple ethnic groups investigation. JAMA 2001 Jul 11;286:180-7. \\ QUESTION: Can the Framingham scores, originally developed in a white middle class \\ population, predict the risk for coronary heart disease (CHD) in ethnically diverse \\ populations?
}

Source of funding: National Heart, Lung and Blood Institute.

For correspondence: $D r$ R B D'Agostino, Sr. Department of Mathematics and Statistics, Boston University, 111 Cummington Street, Boston, MA 02215, USA.Ralph@bu.edu.

\section{Design}

Validation of the Framingham scores in 6 ethnically diverse cohorts.

\section{Setting}

USA.

\section{Patients}

The Framingham cohort included white participants without CHD. The validation cohorts included the Atherosclerosis Risk in Communities Study (white and black participants), the Physicians' Health Study (white men), the Honolulu Heart Program (Japanese-American men), the Puerto Rico Heart Health Program (Hispanic men), the Strong Heart Study (Native American participants), and the Cardiovascular Health Study (white participants).

\section{Description of prediction guide}

The Framingham cohort was used to develop sexspecific Cox proportional-hazards regression functions relating $\mathrm{CHD}$ risk factors (age, blood pressure, cholesterol concentrations, current smoking, and presence of diabetes) to the occurrence of coronary death or myocardial infarction (CHD events). Functions relating the same CHD risk factors to $\mathrm{CHD}$ events were calculated by using each validation cohort's own data.

\section{Main outcome measures}

The Framingham scores were compared with the scores of each validation cohort for accuracy in predicting relative risks (RRs) for CHD risk factors, ability to discriminate between those who have CHD events and those who do not, and ability to predict CHD events in each cohort.

\section{Main results}

The table shows the 5 year RRs for CHD risk factors from the Framingham cohort and the ranges of RRs from the validation cohorts. Discrimination was similar between the Framingham scores and the scores for each validation cohort. The Framingham scores predicted the 5 year CHD risk in white and black participants but overestimated CHD risk in Japanese-American and Hispanic men and native American women. After recalibration, which required data on each cohort's CHD risk factor prevalence and $\mathrm{CHD}$ event rates, these overestimations were corrected.

\section{Conclusion}

The Framingham scores predicted the risk for coronary heart disease (CHD) in white and black populations, but they need recalibration for risk factor prevalence and CHD event rates before they can be used in other ethnic populations.
Sex-specific 5 year relative risks (RRs) for coronary heart disease (CHD) risk factors for the Framingham cohort and RR ranges for CHD risk factors for the 6 validation cohorts

\begin{tabular}{|c|c|c|c|c|}
\hline \multirow[b]{2}{*}{ CHD risk factors } & \multicolumn{2}{|c|}{$\begin{array}{l}\text { Framingham } \\
\text { cohort }\end{array}$} & \multicolumn{2}{|c|}{6 validation cohorts } \\
\hline & Men & Women & Men & Women \\
\hline Age & 1.05 & 1.19 & 1.01 to 1.07 & 0.88 to 2.83 \\
\hline $\begin{array}{l}\text { Blood pressure }(\mathrm{mm} \mathrm{Hg}) \text { (systolic } \\
\geqslant 160 \text {, diastolic } \geqslant 100 v \text { systolic } \\
<130 \text {, diastolic }<85)\end{array}$ & 2.45 & 1.84 & 1.40 to 3.26 & 2.07 to 8.86 \\
\hline $\begin{array}{l}\text { Total cholesterol concentration }(\mathrm{mg} / \mathrm{dl}) \\
\geqslant 280 \vee 160 \text { to } 199\end{array}$ & 2.29 & 2.44 & 1.57 to 8.97 & 1.48 to 3.21 \\
\hline $\begin{array}{l}\text { High-density lipoprotein cholesterol } \\
\text { concentration }(\mathrm{mg} / \mathrm{dl}) \geqslant 60 \vee 45 \text { to } 49\end{array}$ & 0.63 & 0.58 & 0.55 to 1.48 & 0.47 to 2.87 \\
\hline Diabetes & 1.69 & 2.38 & 1.40 to 4.29 & 2.01 to 8.63 \\
\hline Current smoking & 2.07 & 2.65 & 1.02 to 1.94 & 0.55 to 3.92 \\
\hline
\end{tabular}

\section{COMMENTARY}

A Medline search with the terms Framingham, cardiovascular disease, and risk factors retrieves $>1000$ articles. If the studies based on the Framingham cohort do not generalise well to other populations, then these articles may be of interest only to physicians who work with patients similar to those living in the white, middle class town of Framingham 30 miles west of Boston.

To test the transportability of the Framingham regression model, D'Agostino et al used 6 ethnically diverse cohorts to examine 3 aspects of the model's performance: the stability of the RRs for each of the factors in the model across different cohorts; model discrimination, which measures the model's ability to properly rank-order the patients by their risk for CHD; and model calibration, which tests the accuracy of the model across subsets of the population with varying degrees of risk.

The variables in the Framingham CHD risk model include age, blood pressure, total and high-density lipoprotein cholesterol concentrations, presence of diabetes mellitus, and current smoking status. With several interesting exceptions, the RRs associated with each risk factor were stable across ethnic groups, showing that the relative importance of these CHD risk factors is similar in diverse populations and is well captured by the Framingham model. Similarly, except for the Strong Heart Study database, the discriminatory power of the Framingham model was virtually as good as the best Cox model fitted directly to each of the databases. Even after controlling for the risk factors in the model, the participants in the Japanese, Hispanic, and native American cohorts had lower overall CHD risk than did those in the Framingham cohort.

For clinicians caring for diverse populations, the relative importance of conventional CHD risk factors is roughly the same across different ethnic groups, even when the absolute risk across these groups may differ. Clinicians who use Framingham equations to estimate CHD risk in individual patients should be aware that the current equations systematically overestimate risk in some ethnic groups unless they have been recalibrated for use in these groups.

David M Kent, MD, MS John Griffith, $\mathrm{PhD}$ New England Medical Center, Boston, Massachusetts, USA 